\title{
Application of Modern Surveying and Mapping Technology in Housing Management
}

\author{
Wu Fan \\ Department of Building Engineering, Nanjing Forestry University, Nanjing, China \\ 565006198@qq.com
}

Keywords: House Surveying and Mapping; Computer technology; Characteristic

\begin{abstract}
In recent years, with the continuous development and improvement of China's land resources management level, surveying and mapping technology has been widely used in the current housing management. Through the detection of land and housing resources by surveying and mapping technology, people can achieve efficient planning and management of the housing, which places an important role in promoting the management of land resources in China. Housing surveying and mapping is a special branch of modern surveying and mapping, and its scope of the measurement has a specific range, which generally refers to the houses and some lands related to the houses. The surveying and mapping technology in our country has realized the digitization and high efficiency of surveying and mapping, and it is now on the way toward the information technology. It has become a scientific problem to be solved that we should widely use the advanced mapping technology in the management of housing resources, so as to provide the necessary technical means for the whole house surveying and mapping, thus realizing the goal of serving the reform of the housing system.
\end{abstract}

\section{Introduction}

Housing, also known as "real estate", has the characteristics of practicality, economy, immobility, and so on. It is a very important resource for production, and it has strong economic and legal significance. With the acceleration of urbanization in our country, China's investment intensities in fixed assets and real estate are increasing, the proportion of the investment in total fixed asset investment has gradually increased, and in some cities, such as Beijing, Shanghai and other large cities, property management business is very large and is in rapid growth, therefore, in order to curb the excessive growth in housing prices, China continues to strengthen the management and regulation of the real estate market, Chinese people are also making more and more urgent desires for strengthening the management and regulation of the real estate market by our government. The current society is a highly information oriented society, in which all walks of life have set off a wave of large-scale information construction, and housing management industry is also facing severe challenges, therefore, it is urgent for the housing authority to change the way of management, improve the information management as well as scientific and technological level, so as to meet the growing demand for property management and services. By using database technology, computer network technology and other information technology, and establishing housing management system, we can manage all types of housing information, which, on the one hand, can serve in the internal affairs of the housing authority, on the other hand, it can provide information services, so as to provide decision-making basis for the implementation of urban management at all levels of government and its functional departments, such as urban planning, housing security, demolition, property management, etc.. Therefore, the research and construction of the real estate management decision support system can realize the transformation from the traditional file based management to information management, as well as that of the basic data management and display to the information mining and decision support services, thus standardizing business processes, and improving the management level. 


\section{The Application of Surveying and Mapping Technology in Real Estate Surveying and Mapping}

Application of GPS Technology in Real Estate Surveying and Mapping. GPS technology, which is a global satellite monitoring and measurement technology, plays a very important role in the housing surveying and mapping. In the housing construction project, GPS technology has been applied in various aspects, which improves the accuracy and efficiency of the measurement. In the actual mapping process, people often use GPS positioning to select the data collection, and through the three-dimensional positioning of its coordinates, GPS technology can determine the structural shape of a building, and analyze the complicated sharing calculation. According to the rules in Technical Code for Surveying and Mapping of Building Area in Shenzhen, errors of the adjacent control point in measuring points of division shall not be more than $5 \mathrm{~cm}$, thus it requires that the measurement accuracy to be accurate to cm, however, GPS technology can achieve such a standard. At the same time, the application of GPS technology provides an accurate data basis for the establishment of GIS database.

RTK technology is a conventional GPS measuring method, and static, fast static, dynamic measurements all need to be solved in order to obtain centimeter level accuracy, while RTK is a method which can obtain centimeter level positioning accuracy in real time in the field, and it adopts the method of real-time kinematic, thus is a major milestone in GPS applications, what's more, it brings a new dawn for the engineering lofting, topographic mapping, and control surveying, which greatly improves the efficiency of the operation. RTK technology is being used more and more widely in real estate surveying and mapping, and when using RTK technology to locate the land, the receiver of the base station can transmit the observed data and available data to the GPS receiver of the mobile station, and the mobile station can not only quickly solve the ambiguity of the whole week, but also solve the real time dynamic position of convective motion at $\mathrm{cm}$ level. In short, applying the RTK technology to the specific locations, we can realize centimeter-level accuracy.

Application of GIS Technology in Real Estate Surveying and Mapping. GIS technology, which is geographic information system (GIS) technology, is a technology that has been developed with the development of computer technology, and it has many functions, such as the production of spatial data, the drawing of graphics, and the multi- way query and data management. As shown in Figure 2-1, GIS technology uses geographic information system platform to effectively deal with the data collected. And in the process of real estate surveying and mapping, a variety of data need to be collected, data include the length of the house, the measurement data of the building elevation and height between floors and so on. GIS technology is divided into three systems, including real estate surveying and mapping system, project surveying and mapping, and real estate mapping subsystem.

All kinds of data on housing is an important part of real estate geographic information system, and it is natural that the housing data is generated and acquired in different departments, and because the natural property of the house and the production of the spatial geographic attribute data are completed by the surveying and mapping work, therefore, the social and cultural attributes of housing are obtained in the real estate management. What's more, establishing the relationship between housing mapping and housing management, unified data classification and coding standards, as well as normative data flow is particularly important both in large-area housing mapping and the initial establishment of housing geographic information system. It is well known that housing surveying and mapping serves for housing management, then the demand for data from the housing management provides a higher standard for the data obtained from the survey, according to this demand, and combined with the characteristics of large database technology and housing surveying and mapping, establishing a unified data classification and coding standard is therefore becoming very necessary, and under such condition, the uniqueness, accuracy and security of data are the basis of establishing the standard of data classification and coding for the housing geographic information system.

Simply speaking, component based GIS refers to that by using the object oriented technology 
and component based software system, as well as the basic thoughts of basic platform and application system, it can divide the main function modules into several components, and different components perform different functions. Each component, as well as different components and other non components, can be easily integrated through visual software development tools, thus forming the final infrastructure platform and application system.

Component based software technology has become one of the trends of software technology. And in order to adapt to the trend of this technology, component based GIS, like other software, has been or is undergoing a revolutionary change, and this means that it transforms from obtaining all the systems and software having secondary development functions from manufacturers in the past to re develop by users themselves after being provided with the components.

Application of RS Image Technology in Real Estate Surveying and Mapping. RS technology, which also refers to the remote sensing technology, is mainly used for spatial data acquisition. RS imaging technology provides a three-dimensional mapping of real estate mapping, and it plays an important role in the development of real estate surveying and mapping. Technical Specification for Surveying and Mapping of Building Area specifies that the scale of the completed construction drawing shall be 1:500, and when the building area is relatively larger, the scale can be 1:1000, what's more, remote sensing images can be obtained by using multi spectral aerial photography and high-resolution remote sensing satellites, therefore, the image of each scale can be obtained quickly. At present, the RS imaging technology can accurately survey the housing, which has broad prospects for development in this area.

Application of JSP Technology. JSP is a kind of technology on system design and development, which was originally proposed by the company of Sun, later, many large software companies were also involved in the optimization and improvement of JSP technology, therefore, they continuously improved the performance of the JSP page display, and at present, it has become a relatively mature WEB display window. JSP support embedded Java source code and Java script. Its standardization is on the basis of Servlet, by which it can complete the system design and development as far as possible. JSP is a dynamic technology, which is similar to ASP, but the difference between the two is that they use different technical systems, thus it is natural for the two to have different application environments. JSP pages are generally composed of HTML, CSS, script code, having *.jsp as its file-name extension. JSP technology page is not dependent on the system, therefore, using JSP technology to achieve the system page design and application scripts can bring scalability and portability. What's more, it is mainly on the server side. Work-flow of JSP is as shown in Figure 1.

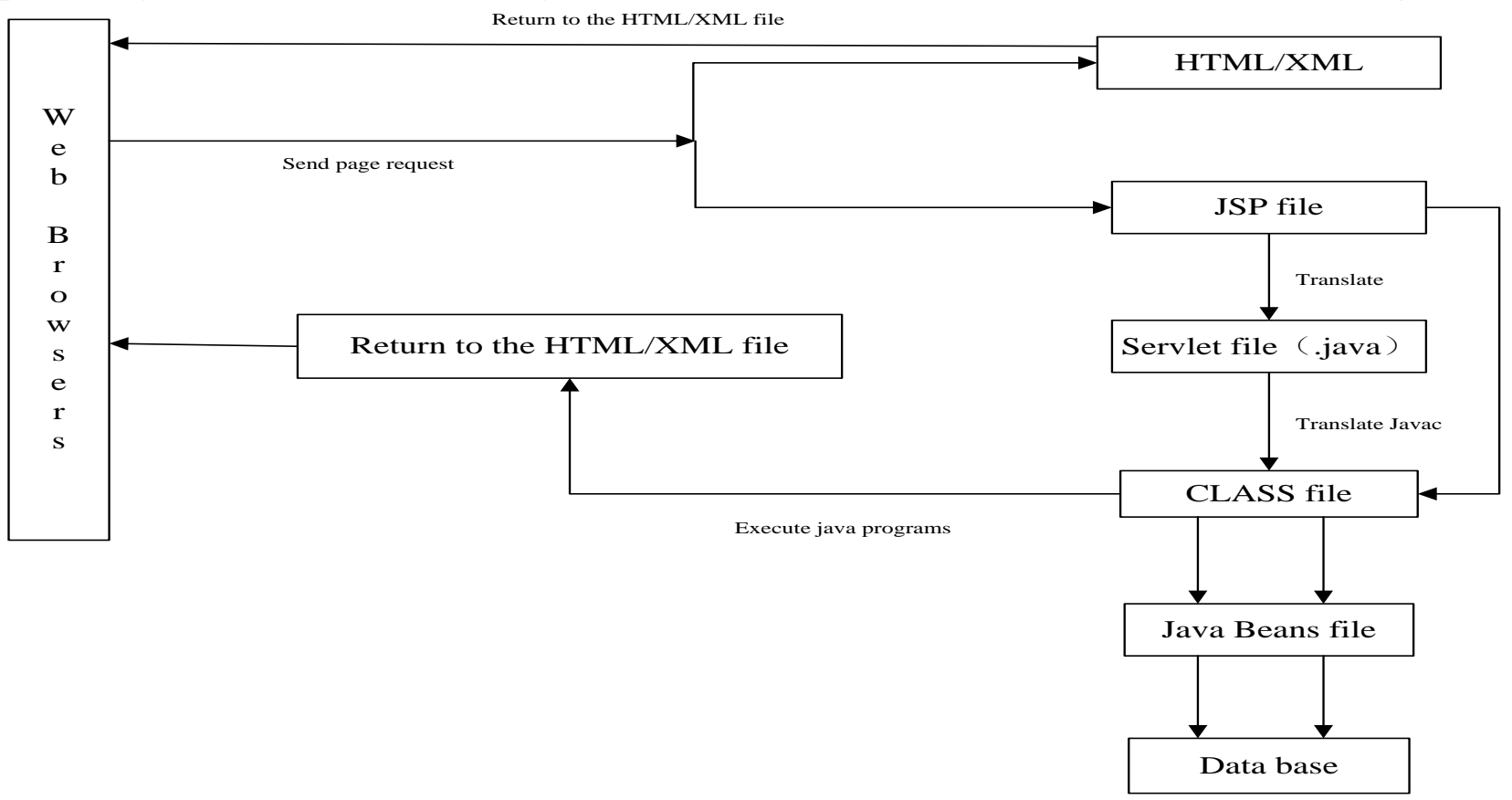

Fig. 1 Work-flow of JSP

Application of SSH Framework System. Housing surveying and mapping can use the MVC 
model to design data, using the framework of Struts2.0+Spring+Hibernate to develop, and the benefits of using the MVC model refer to the separation of business logic and data services, which is a common design pattern, and has become a design specification. The MVC model is composed of three important components, namely controller, view and model. The three components are independent of each other in business processing, and for the request information of the model, the controller is used to receive and request, and then the controller processes the data back to the view, and finally displays the data on the page. SSH refers to Struts, Spring, and Hibernate. Struts2 is a great MVC framework, which is combined with the design idea of MVC, and is a kind of controller, whose core component is the controller, which controls the business process of the framework of the whole system. Struts2 is divided into two kinds of controllers, which are business controller and front-end controller. Struts2 provides powerful view components, including FLEX, JSP, HTML, and so on. In this series of processes, Struts2 is not designed to model processing phase. The model phase is generally processed by Spring, which is a lightweight framework, and which includes facing the section and control inversion, and it mainly realize the persistence of business process and the reversal of business rules flow. In the aspect of data relation, the Hibernate framework is used by it to encapsulate the data. Therefore, SSH realizes the separation of controller, view and model, and realizes the characteristics of low coupling and high cohesion. Spring is an open source framework, which is divided into facing the section and control inversion, and Spring is a practical framework for the development of complex applications. As a container, The main role of Spring is to deal with the business relationship between Struts and Hibernate, what's more, it serves as a bridge for the program and serves as the underlying service of the system, thus the management and implementation of the entire system is relied on Spring. Hibernate is a kind of object relational mapping framework, which mainly obtain the correlation between application and database through data connection pool, what's more, Hibernate can be run in the JAVA program, and it can also run directly on the page. With the development and update of Hibernate technology, the CMP link pool is gradually replaced, which solves the problem of data persistence. Hibernate includes five core interfaces, and they are Query, Session Factory, Session, Transaction and Configuration.

\section{Conclusions and Prospects}

Housing surveying and mapping has various functions, and in terms of its functions in law, the housing surveying and mapping data can not only effectively deal with all kinds of property rights disputes in the housing management industry, make clear the legal property rights, stabilize the property rights, but also can provide the basis for the management of property rights. In terms of its economic functions, housing surveying and mapping data can provide relevant data for housing transactions, leasing activities, tax collection and housing price assessment, at the same time, it can ensure the smooth development of housing insurance services and housing mortgage loans. In the social aspect, through the collation and statistics of the data obtained from the surveying and mapping of houses, we can get the data which is helpful to the government decision-making, and this also has a very important significance for the transformation of dilapidated houses, the old city and the housing system reform and urban construction and other work. At the same time, it can provide relevant information and basic data for city greening, environmental protection, public utilities, municipal engineering, surveying and mapping, electrical transport, communications, tourism, water conservancy, underground pipe network, education, social security etc..

\section{References}

[1] Gao Bangsheng. Discussion on Quality Management of Real Estate Surveying and Mapping[J] . Heilongjiang Science and Technology Information 2008(18):28-30.

[2] Li Yongxi. The Characteristics and Technical Analysis of Real Estate Surveying[J]. China New Technologies and Products, 2010(14):39-41.

[3]Wang Dandi. ORACL Optimization Strategy of Database Structure and Index[J].Journal of 
Xihua University, 2009, 29(2):189-190.

[4]Zhao Jing. GIS The Application of Digital Land Construction[J]. China Construction Magazine, 2008, (6):43.

[5] Huang Yongqi, Wei Heyong, Xie Yubo. Implementation of Thematic Map Making Based on ArcGIS Engine[J]. Anhui Agricultural Sciences. 2007,1(14):4144-4147.

[6] Wu Bo. Design and Implementation of Universal Privilege Management Module Based on Database[J].Computer Security, 2006, (7):9-10.

[7]Chen Shupeng, Lu Xuejun, Zhou Chenghu. Introduction to Geographic Information System[M]. Beijing: Science Press, 2009:25

[8] Bian Fuling. Principles and Methods of Geographic Information System[M]. Beijing: Surveying and Mapping Press, 2000, 2010:21-23

[9] Han Zaizhan, Fu Yunpeng. On the Quality Assurance of Real Estate Surveying and Mapping Results[J]. Heilongjiang Science and Technology Information, 2011(11) .

[10] Li Mou. Research on the Development of Real Estate Surveying and Mapping Management Based on the Practice of Real Estate Surveying[J]. Technology Information, 2010(4).

[11] Shi Yuan. Discussion on the Quality Control of the Main Links in the Process of Real Estate Surveying and Mapping[J].Jiangxi Building Materials, 2014, 04:237-238.

[12] Zhang Li. Analysis of Related Problems in Real Estate Surveying and Mapping[J].Technology and Enterprise, 2014,09,89. 